\title{
Place, people, politics and health
}

Previously published at www.cmaj.ca

\section{A Thousand Dreams: Vancouver's Downtown Eastside and the Fight for its Future \\ Larry Campbell, Lori Culbert and Neil Boyd Greystone Books; 2009.}

$\mathrm{T}$ here are certain neighbourhoods that have come to symbolize societal failure. ${ }^{1}$ The South Bronx area, with its multiple health and other social issues in New York City may be the most well known of these problem areas in the United States; Vancouver, British Columbia's Downtown Eastside may be the most well known in Canada.

A Thousand Dreams is an informal history of the Downtown Eastside, with an emphasis on the period after the 1986 Expo up to just before the 2010 Olympics. Campbell is a former coroner and mayor of Vancouver, Boyd a criminologist at Simon Fraser University in Vancouver and Culbert an investigative reporter with the Vancouver Sun. While the book does contain a moderate amount of data, it is far closer to being a political memoir of the first author than a closely reasoned, data-driven analysis.

The story is told primarily from a focus on the efforts of heroes fighting against many different opponents. The heroes are a combination of Downtown Eastside residents struggling to maintain the positive traditions of and obtain services for a low-income neighbourhood, and sympathetic outsiders who advocate for the neighbourhood within the larger political context of the city, and the provincial and federal governments.

The heroes are fighting many opponents. The first, and perhaps the most damaging and persistent are psychoactive drugs. Interestingly, the first drug problems involved inexpensive beer

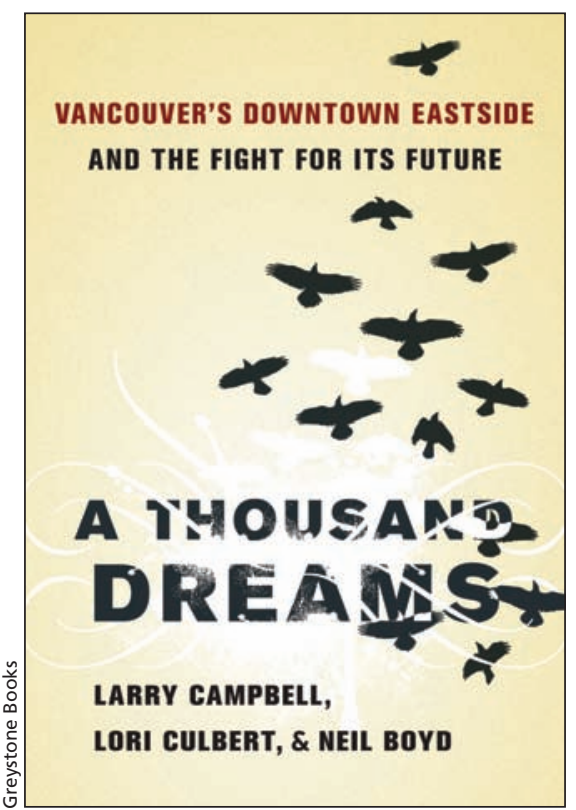

and rice wine, demonstrating that drugs need not be illegal to cause serious individual and social problems. Cheap alcohol was followed by heroin, injected cocaine, smoked (crack) cocaine and methamphetamine. All of these drugs caused addiction, which compounded other health and social problems among persons living in the Downtown Eastside. Several of the drugs involved led to additional severe problems: Injection drug use was the primary driver of the large HIV/AIDS incidence in the Downtown Eastside and crack cocaine addiction appears to be particularly debilitating for women, often leading them to engage in survival sex. The dangers of practising survival/commercial sex are highlighted in one chapter on a serial killer.

Inadequate housing for low-income persons and persons needing supportive services is the second major opponent highlighted throughout the book. Homelessness increased in the Down- town Eastside at least through the last survey conducted in 2007. Increasing housing/decreasing homelessness would not solve all problems, but as the authors note repeatedly, it is difficult to stabilize the lives of persons who are addicted and/or have mental illness unless adequate housing is provided.

Commercial development is the third opponent. Property in the Downtown Eastside is extremely valuable for commercial development, both retail and high-end housing. Such development could easily displace the "injured" persons living in the Downtown Eastside and disrupt the functioning of the community organizations. Thus, the activists must not only work for increasing housing and social services, but oppose gentrification of the neighbourhood.

The climax of the narrative is the implementation of InSite, a "safer injection facility," which provides drug injectors a place where they can inject under medical supervision. (They must, however, bring in their own drugs.) Opening InSite was a major campaign issue in Campbell's campaign for mayor of Vancouver, and his election was an indication of strong public support for the facility. InSite does provide sterile injection equipment, immediate medical attention in the case of overdose and ready linkage to other health and social services for drug users. The current Canadian federal administration is attempting to close InSite and the issue is being appealed in the courts.

Despite the heroic efforts described in A Thousand Dreams, the future of the Downtown Eastside is unclear. There certainly have been important victories: The social services being provided do save lives and the HIV/AIDS epidemic is being brought under control. The 2010 Olympics, a major priority for 
Campbell as mayor, did lead to increased social housing (along with increased gentrification according to researchers Mark Tyndall and Evan Wood). The Downtown Eastside, however, still has some of the worst health statistics of any place in BC. The Harm Reduction perspective may be the most appropriate framework for addressing the multiple health and social problems of areas like the Downtown Eastside it is possible to greatly ameliorate addiction and mental health problems - but we are far from either preventing or solving such problems.

There are a few stylistic and analytic issues with the book. A who's who of characters would have made the historical narrative easier to track and a timeline would have allowed readers to construct an integrated picture of events. (Did the de-institutionalization of the mentally ill overlap with the heroin or the cocaine epidemic?) Hav- ing some tables or figures would also help organize the narrative. Numbers of overdose deaths, homeless persons and housing units are frequently given in the text; having tables of these over time would give a clearer sense of the context of the political and community activism.

The absence of organized data prevents the reader from fully assessing the validity of the many different policies advocated by the authors and from developing any alternative conclusions. Urban policies, however, do not spring forth from rigorous, emotionally neutral analyses of the best available data. Rather such policies are typically the result of passionate advocates working in a very complex political environment. While A Thousand Dreams may be very light on formal data analyses, it is very rich in passionate advocacy (often running into harsh economic and political realities).
A Thousand Dreams provides considerable insight into multiple urban health problems and the resilience of urban communities. For the scientific data, one may turn to the many research reports of the University of British Columbia Centre for Excellence in AIDS, and for the perspective of young drug users in the Downtown Eastside, I would suggest the recent paper by Fast and colleagues. ${ }^{1}$ But this book is useful reading for anyone wanting to understand the complexities of urban health.

\section{Don C. Des Jarlais PhD}

Edmond de Rothschild Chemical

Dependency Institute

Beth Israel Medical Center

New York City, USA

\section{REFERENCE}

1. Fast D, Small W, Wood E, et al. The perspectives of injection drug users regarding safer injecting education delivered through a supervised injecting facility. Harm Reduct J 2008;5:32. 